\title{
GAMBARAN PYSCHOLOGICAL WELL BEING PADA LANSIA YANG BERSTATUS JANDA
}

\author{
Nikita Cestin Nalle ${ }^{1}$, Christiana Hari Soetjiningsih ${ }^{2}$ \\ Email : nikitacestin@gmail.com ${ }^{1}$ \\ Fakultas Psikologi Universitas Kristen Satya Wacana Salatiga ${ }^{1,2}$
}

\begin{abstract}
The purpose of this research is to know psychological well-being to the widowed elderly after their husbands' death and what the factors that influence the widowed elderly when their husbands' death. This research is done to the widowed elderly by using phenomenological qualitative approach. Interpretative phenomenological analysis (IPA) is used of the data analysis. This research was successful to identify the psychological well-being. Both of the participants were able to accept their condition as widowed elderly and overcome their bad experiences in the past by getting social support from their children, joining positive activities outside of their houses, and building a good relationship with God. The next researchers who are interested to do a research about psychological well-being to the widowed elderly can research the causes of divorce or another condition.
\end{abstract}

Keywords : Widowed Elderly; Husbands' Death; Psychological Well-Being; Social Support; Relationship with God

\begin{abstract}
Abstrak
Penelitian ini bertujuan untuk mengetahui gambaran kesejahteraan psikologis (psychological well-being) pada lansia yang berstatus janda pasca kematian pasangan dan faktor apa saja yang memengaruhi kesejahteraan psikologis (psychological well-being) pada lansia yang berstatus janda pasca kematian pasangan. Penelitian ini dilakukan pada lansia janda dengan menggunakan pendekatan kualitatif fenomenologis. Data dianalisis menggunakan interpretative phenomenological analysis (IPA). Penelitian ini berhasil mengidentifikasi aspek kesejahteraan psikologis. Kedua partisipan mampu menerima kondisinya sebagai lansia janda dan mengatasi pengalaman buruknya di masa lalu, dengan mendapatkan dukungan sosial dari anak-anak, mengikuti kegiatan positif di luar rumah, dan terus membangun hubungan dengan Tuhan. Bagi penelitian selanjutnya yang tertarik untuk meneliti psychological well-being pada lansia janda dapat meneliti pada lansia janda akibat perceraian atau kondisi lainnya.
\end{abstract}

Kata Kunci : Lansia Janda; Kematian Pasangan; Psychological Well-Being; Dukungan Sosial; Hubungan Dengan Tuhan

\section{PENDAHULUAN}

Manusia mengalami berbagai proses dalam kehidupan, salah satunya adalah proses perkembangan. Perkembangan dapat diartikan sebagai serangkaian perubahan progresif yang terjadi akibat dari proses kematangan dan pengalaman (Hurlock, 1999). Proses perkembangan yang terjadi dari bayi, anak, remaja, dewasa dan sampai pada lansia. Tahap terakhir dalam rentang kehidupan sering dibagi menjadi usia lanjut dini, yang berkisar 60-70 tahun dan usia lanjut yang mulai pada usia tujuh puluh sampai akhir kehidupan seseorang (Hurlock, 1999). Lanjut usia merupakan suatu proses berkelanjutan dalam kehidupan yang ditandai dengan berbagai perubahan kearah penurunan, seperti mengalami penurunan fisik dan para lansia juga harus menghadapi masalah psikologis dalam kehidupan mereka. 
Proses menjadi tua seseorang dipandang dalam hubungannya dengan diri sendiri dan dengan lingkungannya (Monks, 1984). Havighurst (Hurlock, 1999) menyatakan bahwa tugas perkembangan masa tua yaitu menyesuaikan diri dengan menurunnya kekuatan fisik dan kesehatan, menyesuaikan diri dengan masa pensiun dan berkurangnya income (penghasilan) keluarga, menyesuaikan diri dengan kematian pasangan hidup, membentuk hubungan dengan orang-orang yang seusia, membentuk pengaturan kehidupan fisik yang memuaskan, dan meyesuaikan diri dengan peran sosial secara luwes. Jika individu tersebut gagal dalam menguasai tugas perkembangannya maka terdapat dua macam konsekuensi yang serius dari kegagalan tersebut, salah satunya adalah pertimbangan-pertimbangan sosial yang kurang menyenangkan yang tidak dapat dihindari. Konsekuensi lain adalah dasar untuk penguasaan tugas-tugas berikutnya dalam perkembangan menjadi tidak adekuat (Hurlock, 1999).

Kebutuhan psikologis merupakan faktor penting dalam kehidupan seseorang dan menjadi semakin penting dalam kehidupan seorang lansia, karena lansia mengalami berbagai perubahan dan kemunduran yang menyebabkan kehidupan lansia berubah dan memunculkan kebutuhan psikologis yang berbeda dengan kebutuhan psikologis pada masa anak-anak, remaja maupun dewasa. Kebutuhan psikologis ini harus dapat terpenuhi karena apabila tidak terpenuhi maka dapat menimbulkan permasalahan psikologis pada seseorang. Lansia dapat mengalami permasalahan psikologis, seperti adanya perasaan tak berguna, perubahan pada pola hidup, kecenderungan untuk berpikir bahwa ia tidak dibutuhkan lagi, merasa sedih dan kesepian karena kehilangan pasangan hidup dan teman sebaya (Hurlock, 1999).

Ciri-ciri usia lanjut cenderung menuju dan membawa penyesuaian diri yang buruk daripada yang baik dan kepada kesengsaraan dari pada ke kebahagiaan (Hurlock, 1999). Proses penyesuaian diri sangat dibutuhkan ketika individu kehilangan pasangan hidup. Kehilangan pasangan hidup dapat terjadi karena perceraian dan kematian pasangan. Namun kebanyakan lansia yang mengalami kehilangan pasangan hidup disebabkan oleh kematian pasangan hidup (Hurlock, 1999).

Kematian pasangan hidup membuat seseorang mengalami perubahan status 
dan peran sehingga menyandang status sebagai duda atau janda dan mengalami permasalahan psikologis dalam kehidupannya, terutama bagi lansia. Hidup menjanda atau menduda berbeda bagi lansia pria dan wanita, kematian pasangan merupakan suatu hal yang tidak mudah, terkhususnya dalam melakukan penyesuaian (Sari, 2006). Pria dan wanita sama-sama mengalami penurunan kesehatan mental setelah kematian pasangan, tetapi wanita memiliki tingkat kesedihan, depresi, dan kecemasan yang lebih tinggi dibandingkan pria (Ghali, 2015).

Dampak yang terjadi ketika masa menjanda merupakan masalah yang serius bagi wanita dibandingkan pria, hal ini diperkuat dari hasil penelitian yang dilakukan oleh lembaga independent age yang mengatakan bahwa wanita hampir dua kali lebih mungkin untuk merasa kesepian, sedih, bahkan depresi, setelah berkabung ketimbang dengan pria. Terlebih wanita yang telah berusia lebih dari 50 tahun ( fenomena tersebut menunjukan bahwa wanita terkhususnya lansia wanita memiliki masalah ketika mengalami kematian pasangan hidup.
Dampak lainnya akibat pengaruh negatif jangka panjang masa menjanda adalah lebih banyak disebabkan oleh rendahnya faktor sosial ekonomi daripada karena faktor menjanda itu sendiri, karena alasan tersebut maka kehilangan pasangan hidup lebih dianggap sebagai masalah wanita (Hurlock, 1999). Akibat pengaruh negatif yang muncul membuat lansia janda dapat berkembang dengan baik berdasarkan potensi diri yang dimilikinya. Dampak dari setiap masalah yang dihadapi lansia janda menunjukan betapa pentingnya psychological well-being pada kehidupan lansia janda. Sehingga cara yang dapat dilakukan oleh para lansia janda adalah dengan berusaha mencapai kesejahteraan psikologis (psychological well-being).

Kebahagiaan dan kesuksesan lansia dapat tercapai dengan terpenuhinya kebutuhan akan kesejahteraan psikologis (psychological well-being) (Desiningrum, 2014). Kesejahteraan psikologis (psychological well-being) dipandang sebagai suatu aspek penting dalam proses penuaan yang positif, dan juga menjadi komponen yang sangat diperlukan dalam perkembangan sepanjang hidup serta dalam proses adaptasi (Ryff, 1989). Kesejahteraan psikologis merupakan 
kemampuan individu untuk menerima dirinya apa adanya (self-acceptance), membentuk hubungan yang positif dengan orang lain (positive relation with others), memiliki kemandirian dalam menghadapi tekanan sosial (autonomy), penguasaan lingkungan (enviromental mastery), memiliki tujuan dalam hidupnya (purpose in life), serta mampu merealisasikan potensi dirinya secara kontinu (personal growth) (Ryff,1989). Secara psikologis manusia yang memiliki sikap positif terhadap diri sendiri dan orang lain adalah manusia yang mengakui dan menerima berbagai aspek yang ada dalam dirinya, baik yang bersifat baik maupun buruk serta merasa positif dengan kehidupannya (Ryff \& Keyes, 1995). Begitu juga lansia janda, harus menerima dan bersikap positif terhadap perubahan status atau dapat beradaptasi dengan kematian pasangan hidup sehingga dapat berkembang dengan baik dan memiliki kesejahteraan psikologis.

Seseorang dapat dikatakan telah mencapai kesejahteraan psikologisnya jika telah mencapai berbagai aspek dari kesejahteraan psikologis (psychological well-being) itu sendiri. Menurut Ryff (1989) kesejahteraan psikologis (psychological well-being) dirumuskan kedalam enam dimensi yaitu: penerimaan diri (self acceptance), hubungan positif dengan orang lain (positive relation with others), otonomi (autonomy), penguasaan lingkungan (environmental mastery), tujuan hidup (purpose in life), dan erkembangan pribadi (personal growth).

Selain itu menurut Ryff (1999) terdapat faktor-faktor yang memengaruhi kesejahteraan psikologi yaitu usia, gender, status sosial ekonomi, pendidikan, budaya dan dukungan sosial. Dengan demikian, ketika lansia janda telah merasa berhasil melalui memenuhi tahapan perkembangannya dengan perasaan yang positif dan mampu memenuhi keenam kriteria secara positif, maka dapat dikatakan lansia tersebut mencapai Psychological Well-Being.

Hasil wawancara awal yang dilakukan peneliti pada kedua partisipan terdapat beberapa aspek kesejahteraan psikologis yang sudah terpenuhi dan juga terdapat beberapa aspek yang belum terpenuhi. Salah satu partisipan mengalami masalah akibat kematian pasangan hidup, yaitu tidak menyangka suaminya akan meninggal terlebih dahulu dan juga penerimaan diri pada kematian pasangan hidup membutuhkan waktu yang lama agar dapat menerima diri dalam 
perubahan status yang terjadi. Sedangkan pada partisipan lainnya tidak memiliki rasa kesepian dan memiliki rasa bersyukur atas kematian pasangan hidupnya.

\section{METODE PENELITIAN}

Penelitian ini menggunakan pendekatan kualitatif fenomenologis dengan mempertimbangkan kekhususan masalah dan ketersediaan jumlah informan dalam penelitian. Informan dalam penelitian ini dipilih melalui teknik purposive sampling dengan kriteria lansia janda dengan usia 60 tahun keatas yang menjanda akibat kematian pasangan hidup maksimal tiga tahun dan memiliki anak. Hal ini didasarkan pada Ekowati (2008) yang menyatakan bahwa rentang waktu kurang lebih tiga tahun merupakan proses untuk dapat menerima dan menyesuaikan diri, karena selama tiga tahun itu kemungkinan untuk masih mengingatingat seseorang yang sudah meninggal akan lebih sering dilakukan.

\begin{tabular}{|c|c|c|}
\hline Partisipan & Partisipan 1 & $\begin{array}{c}\text { Partisipan } \\
2\end{array}$ \\
\hline Usia & 72 tahun & 66 tahun \\
\hline Agama & $\begin{array}{c}\text { Kristen } \\
\text { protestan }\end{array}$ & $\begin{array}{c}\text { Kristen } \\
\text { protestan }\end{array}$ \\
\hline $\begin{array}{c}\text { Masa } \\
\text { menjanda }\end{array}$ & 2 tahun & 3 tahun \\
\hline Jumlah anak & 5 anak & 5 anak \\
\hline $\begin{array}{c}\text { Penyebab } \\
\text { kematian } \\
\text { suami }\end{array}$ & Sakit & Sakit \\
\hline $\begin{array}{c}\text { Waktu } \\
\text { wawancara }\end{array}$ & $\begin{array}{c}\text { 18 Januari } \\
2019\end{array}$ & $\begin{array}{c}\text { 24 Januari } \\
2018\end{array}$ \\
\hline
\end{tabular}

Teknik pengumpulan data yang dilakukan dalam penelitian ini adalah wawancara dengan menggunakan pedoman wawancara. Pertanyaan wawancara yang diberikan berdasarkan keenam aspek dan pertanyaan tidak selalu merupakan urutan yang kaku tetapi atas dasar dinamika yang berkembang selama wawancara. Alat pengumpulan data yang digunakan adalah alat perekam. Proses wawancara diawali sebelumnya dengan membangun raporrt pada semua partisipan. Lokasi penelitian ini bertempat di Kupang, Nusa Tenggara Timur. Teknik analisis data menggunakan interpretative phenomenological analysis (IPA). Dalam penelitian ini, peneliti menggunakan metode respondent validation (Herdiansyah, 2015).

\section{HASIL DAN PEMBAHASAN}

Penelitian ini berhasil mengidentifikasi aspek kesejahteraan psikologis menurut Ryff (1989) yaitu penerimaan diri, hubungan positif dengan orang lain, otonomi, penguasaan lingkungan, tujuan hidup dan perkembangan pribadi.

\section{Penerimaan Diri}

Setelah kehilangan pasangan hidup partisipan 1 merasakan damai sejahtera, walaupun terkadang partisipan mengingat 
ketika suaminya sakit. Tetapi partisipan dapat bangkit dari keterpurukan dengan cara berdoa dan membaca firman Tuhan, karena partisipan percaya bahwa ketika sudah mendekatkan diri kepada Tuhan maka akan diberikan damai sejahtera. Partisipan 2 merasakan sangat terpukul akibat suaminya meninggal, partisipan 2 tidak menyangka kalau suaminya yang meninggal terlebih dahulu karena partisipan 2 yang sudah menderita sakit terlebih dahulu, tetapi setelah itu partisipan 2 sadar bahwa semuanya itu adalah rencana Tuhan sehingga partisipan 2 berserah diri dan menerima peristiwa tersebut dengan ikhlas. Berdasarkan data yang diperoleh, partisipan 2 mengalami peristiwa sesuai tahap yang dikemukakan oleh averill (Santrock, 2002) yaitu tahap terkejut, putus asa dan pulih kembali.

\section{Hubungan Positif dengan Orang Lain}

Kedua partisipan memiliki hubungan yang baik dengan anakanaknya, partisipan 1 sangat bahagia karena anak-anaknya memberikan kasih sayang dan juga perhatian kepada partisipan. Partisipan 2 juga merasa bahagia bersama anak-anaknya, terlebih karena kehadiran cucu yang selalu mengisi hari-harinya. Hubungan kedua partisipan dengan para tetangga dan keluarga juga baik, kedua partisipan tidak merasakan ada perubahan yang terjadi setelah suaminya meninggal. Hubungan kedua partisipan dengan keluarga dan tetangga baik-baik saja sama seperti ketika suaminya masih hidup. Sebagai hamba Tuhan partisipan 1 tetap melakukan pelayanan kasih terhadap sesama. Dukungan emosional dapat membantu lansia-terutama lansia tertuadalam mempertahankan kepuasan hidup ketika menghadapi stres dan trauma, seperti kehilangan pasangan hidup atau anak atau kecelakaan dan penyakit yang mengancam hidup, dan ada kaitan positif dengan kesehatan dan kebahagiaan hidup yang lebih baik, Krause (Papalia, 2009). Selain itu menurut Sari (2006) ketika mendapat dukungan sosial maka dapat membantu individu dalam memberikan dukungan pada individu dengan masalahmasalah yang dihadapinya.

\section{Otonomi}

Setelah kehilangan pasangan hidup partisipan 1 sedikit mengalami kesulitan dalam mengerjakan tugas-tugas rumah tangga karena partisipan mengalami sakit, tetapi partisipan 1 tetap mengerjakan semampunya. Sedangkan partisipan 2 mampu mengerjakan tugas-tugas rumah tangga dengan baik. Ketika mengalami 
masalah kedua partisipan tidak pelayanan di gereja maupun di menceritakan kepada siapapun, melainkan persekutuan doa. Kedua partisipan mereka berdoa kepada Tuhan agar mengakui bahwa ketika melaksanakan diberikan kekuatan dan jalan keluar. pelayanan maka akan membuat mereka Selain itu kedua partisipan sudah merasa bahagia, baik itu bahagia karena anakanak yang telah bekerja, memiliki cucu, dan merasa bahwa mereka adalah anak Tuhan, walaupun partisipan 1 masih terbeban dengan satu anaknya yang belum menikah. Kebahagiaan dapat dirasakan dengan menjalani aktivitas yang disenangi, melakukan kegiatan sehari-hari dengan bersemangat, berpikir positif, berinteraksi dengan lingkungan dan membina persahabatan yang dalam, menjaga hubungan kedekatan yang erat dengan keluarga dan kerabat, bersikap ikhlas terhadap masalah akan sangat membantu manusia dalam memperoleh kebahagiaan (Raharjo, 2007).

\section{Penguasaan Lingkungan}

Perubahan status yang terjadi tidak menghambat kedua partisipan untuk terus melakukan kegiatan di luar rumah. Salah satu tugas perkembangan menurut Havighurst (Hurlock, 1999) adalah menyesuaikan diri dengan kematian pasangan hidup. Kemampuan menyesuaikan diri pada kedua partisipan ditandai dengan aktif dalam melakukan merasakan sukacita dan juga kedua partisipan percaya bahwa dengan kegiatan tersebut dapat menjadi berkat bagi orang lain. Seorang janda berusia lanjut secara psikis tampaknya telah siap untuk menerima kematian suaminya melalui berbagai pengalaman dalam menghadapi kematian, sehingga terbiasa serta dapat mengurangi tekanan sosialnya, kemudian mereka berusaha menyesuaikan dirinya dengan melakukan berbagai kegiatan sosial secara aktif. Menurut teori aktifitas (activity theory) (Santrock, 2002), semakin orang-orang dewasa lanjut aktif dan terlibat, semakin kecil kemungkinan menjadi renta dan semakin besar kemungkinan mereka merasa puas dengan kehidupannya. Di samping itu kegiatan keagamaan tampaknya juga merupakan sumber kekuatan yang utama (Hurlock, 1999).

\section{Tujuan Hidup}

Kedua partisipan memiliki tujuan hidup dan makna hidup yang sama yaitu untuk menyenangkan hati Tuhan dan lebih mendekatkan diri pada Tuhan. Individu dianggap baik menurut dimensi 
tujuan hidup apabila individu tersebut memiliki kepercayaan yang dapat memberinya arti dan tujuan hidup, memiliki pemahaman yang jelas akan tujuan dan arah hidup yang dijalaninya, merasakan arti dalam hidup masa kini maupun yang telah dijalani (Ryff, 1989).

\section{Perkembangan Pribadi}

Dalam menjalani kehidupan setelah menjanda kedua partisipan tidak merasakan adanya perubahan yang terjadi dalam kehidupan mereka. Kedua partisipan merasa biasa saja dengan kehidupan baik itu sebelum maupun sesudah kematian pasangan hidup. Selain itu kedua partisipan sudah merasa puas dengan kehidupan saat ini. Partisipan 1 merasa puas karena melihat anak-anak yang sudah bekerja, yang selalu memberikan perhatian dan kasih sayang bagi partisipan. Dukungan emosional dapat membantu lansia-terutama lansia tertua-dalam mempertahankan kepuasan hidup ketika menghadapi stres dan trauma, seperti kehilangan pasangan hidup atau anak atau kecelakaan dan penyakit yang mengancam hidup, dan ada kaitan positif dengan kesehatan dan kebahagiaan hidup yang lebih baik, Krause (Papalia, 2009). Sedangkan partisipan 2 merasa bahagia ketika selalu ada di hadirat Tuhan walaupun dalam keadaan menderita.

\section{Faktor yang Memengaruhi}

Selain keenam dimensi dari kesejahteraan psikologis yang dimiliki oleh masing-masing partisipan, faktor yang berpengaruh kuat pada kesejahteraan psikologis partisipan adalah religiusitas. Keikutsertaan dan aktivitas para partisipan dalam persekutuan doa dan pelayanan juga terlihat berpengaruh bagi kehidupan lansia janda. Kedua lansia yang menjadi partisipan penelitian menekankan bahwa religiusitas (persekutuan doa dan pelayanan) mempunyai peran dalam kehidupan mereka. Mereka menjadi lebih mempersiapkan diri menghadapi berbagai peristiwa dalam kehidupan mereka sebagai lansia janda. Disamping itu, persekutuan dan pelayanan memiliki peran dalam mengisi waktu kosong dan tentu saja semakin mendekatkan diri mereka kepada Tuhan agar menjadi berkat bagi orang lain, merasakan damai sejahtera dan juga bahagia. Kegiatan keagamaan membantu banyak orang mengatasi berbagai stres dan kehilangan pada masa akhir kehidupan (Papalia, 2009). Persekutuan doa dan pelayanan yang dilakukan kedua partisipan merupakan suatu bentuk dukungan sosial 
berupa layanan spiritual bagi para lansia janda.

\section{PENUTUP}

Kematian pasangan hidup pada lansia janda pada awalnya merupakan hal yang tidak mudah bagi kedua partisipan. Namun kemudian dapat merasakan kesejahteraan psikologis walaupun belum sepenuhnya. Kedua partisipan mengaku bahwa mereka pernah mengingat akan suami mereka, namun kedua partisipan dapat bangkit dari keterpurukan akibat kehilangan pasangan hidup dan mereka sadar bahwa semuanya itu adalah kehendak Tuhan. Hubungan baik bersama anak-anak membuat kedua partisipan merasa bahagia, terlebih lagi bagi partisipan 2 yang merasa bahagia karena kehadiran cucu didalam kehidupannya. Selain itu kedua partisipan juga memiliki hubungan yang baik dengan keluarga dan juga para tetangga di sekitar tempat tinggal mereka. Perubahan status yang terjadi, tidak menghambat kedua partisipan untuk tetap aktif dalam melakukan pelayanan baik di gereja maupun di persekutuan doa yang membuat kedua partisipan merasakan sukacita dan dapat menjadi berkat bagi orang lain. Kedua partisipan memiliki tujuan hidup yang sama, yaitu untuk menyenangkan hati Tuhan dengan cara selalu ada dihadirat Tuhan melalui berdoa dan membaca firman Tuhan. Selain artisipan 1 merasa puas dengan kehidupan saat ini, hal itu ditandai dengan anakanak yang sudah bekerja dan selalu memberikan perhatian dan kasih sayang padanya. Partisipan 2 juga merasa puas dan bahagia dengan kehidupan saat ini ketika selalu ada di hadirat Tuhan.

\section{DAFTAR PUSTAKA}

Desiningrum, D.R. 2014. Kesejahteraan Psikologis Lansia Janda/Duda Ditinjau Dari Persepsi Terhadap Dukungan Sosial Dan Gender. Jurnal Psikologi Undip, 13, 102106.

Ekowati, C.R. 2008. Penyesuaian Diri Terhadap Hilangnya Pasangan Hidup Pada Lansia. Yogyakarta. Fakultas Psikologi: Unversitas Sanata Dharma.

Ghali, E.M.A. 2015. Self-Compassion As A Mediator And Moderator Of The Relationship Between Psychological Suffering And Psychological WellBeing Among Palestinian widowed women. Research on Humanities and Social Sciences, 5, 66-76.

Herdiansyah, Haris. 2015. Metodologi Penelitian Kualitatif untuk Ilmu Psikologi. Jakarta: Salemba Humanika

Hurlock, E.B. 1999. Psikologi Perkembangan: Suatu Pendekatan Sepanjang Rentang Kehidupan. Jakarta: Erlangga. 
Monks, F.J., Knoers, A.M.P., Haditono, S.R. $1984 . \quad$ Psikologi Perkembangan: Pengantar Dalam Berbagai Bagiannya. Yogyakarta: Gajah Mada University Press

Rahardjo, W. 2007. Kebahagiaan Sebagai Suatu Proses Pembelajaran. Jurnal Penelitian Psikologi, 12, 127-137.

Ryff, C. D. \& Keyes, C. L. M. 1995. The Structure Of Psychological WellBeing Revisited. Journal of Personalityand Social Psychology, 69, 719-727.

Ryff, D. C. 1989. Happiness is everything, or is it? Exploration on the Meaning of Psychological Well-Being. Journal of Pesonality Social Psychology, 57, 1069-1081.

Santrock, J.W. (2002). Life Span Development: Perkembangan Masa Hidup, Edisi Lima. Jakarta: Erlangga.

Smith, J. A. \& Osborn, M. 2009. Analisis Fenomenologi Interpretatif. Dalam J. A. Smith. (ed.). Psikologi Kualitatif: Panduan Praktis Metode Riset. (Edisi Terjemahan). Yogyakarta: Pustaka Pelajar.

Papalia., Olds., Feldman. 2009. Human Development: Perkembangan Manusia. Jakarta: Salemba Humanika. 